\title{
ASPECTS REFERRING TO FATIGUE TESTING OF EPOXY POLYMERIC MATERIALS
}

\author{
Costel HUMELNICU*, Valentin AMORTILA, \\ Monica NOVETSCHI, Mihai GINGARASU \\ ”Dunarea de Jos" University of Galati, Faculty of Engineering, Galati, Romania \\ *Corresponding author: costel.humelnicu@ugal.ro
}

\begin{abstract}
Concomitant with the development of new technologies in usage of renewable energies and with the necessity of replacing metal, epoxy polymeric materials are becoming more frequently used. Their main advantages are the reduced weight, high mechanical and corrosion resistance, the possibility to recover, recondition and reutilise the components. Thus, they become suitable for various industries, such as: automobile manufacturing, wind turbine blades, naval industry etc. Increased fragility and low resistance in initiating and developing cracks lead to varied fatigue performance. One way of reducing these disadvantages is to test fatigue in order to observe and analyse its manifestation, before projecting components. This paper presents tests carried on cylindrical epoxy polymeric samples. The samples were manufactured through casting in tubular moulds because of great advantages of this method. The manufacturing time is short, the material usage is maximised and after casting, the samples are smooth and don't have sharp edges. Hence, the risk of unwanted concentrated stress is eliminated. The testing means assessing the samples to variable loading in rotating bending. For a better precision of test results, it is very important that this method could be accurately repeated with samples, preparing them in similar conditions. The results are used to draw Wohler's curve using stress-number of cycles $(S-N)$ as coordinates, specific to the tested material. Finally, the level of maximum stress of a material that resists fatigue, without having any ulterior damage can be determined.
\end{abstract}

Keywords: Fatigue, composites materials, resins epoxy

\section{INTRODUCTION}

Polymeric materials have overtaken the market, which was previously based on conventional materials such as: wood, metal, clay, and lignocellulosic fibers. In the motor industry, in 2017, polymeric materials which were part of a vehicle were, on average, $25 \%$ of its weight [1], taking in consideration both thermoplastic and thermosetting polymers [2].

Another industry which uses increased quantities of polymers, mainly epoxy polymers, is the wind industry. Only one spade of a propeller weights between 14 and 19 tones and can have 120 meters in length [3].

Even more, increased quantities of epoxy resins are used in making boats and yachts, which can weight over tens of tons. [4]

These materials were able to replace classic materials because of the advantages they pose, such as: reduced mass, mechanical resistance to high corrosion levels, the possibility to recover, recondition and reuse etc. However, they have disadvantages too, such as: increased fragility, lower resistance to developing cracks etc. These disadvantages lead to a varied experience of use if the products are exposed to cyclic solicitations.

For examples, the blades of aeolian propellers are exposed to fatigue due to stretching solicitations which appear when they are facing down, then they are exposed to bending when they are with perpendicular on the resistance tower, and then to compression, when facing up. Besides this, the fatigue can appear as a result of bending solicitations caused by wind, or environmental factors and exploitations (temperature, humidity, dust, salty water etc.)

In vehicles, boats and yachts, there are constant vibrations which could influence resistance to fatigue of some of the components made of thermosetting polymers, or, in the case of boats, of their structure. 
To increase the lifespan of a product and minimize the final costs, several fatigue tests can be done on different samples, even from projecting time. These tests have been done especially to metallic materials, to determine the limit of fatigue to a great part of them. In the case of thermosetting polymers, there have been done numerous tests to determine their limit to fatigue too, in the past 20 years and more frequently in the past years.

Fatigue testing of polymeric materials is done through different methods, depending on the type of solicitation or the shape of the samples. Studying relevant literature, it has become obvious that, to this date, there are few fatigue tests on cylindrical samples, made of epoxy resins, which have been exposed to solicitations of rotational bending.

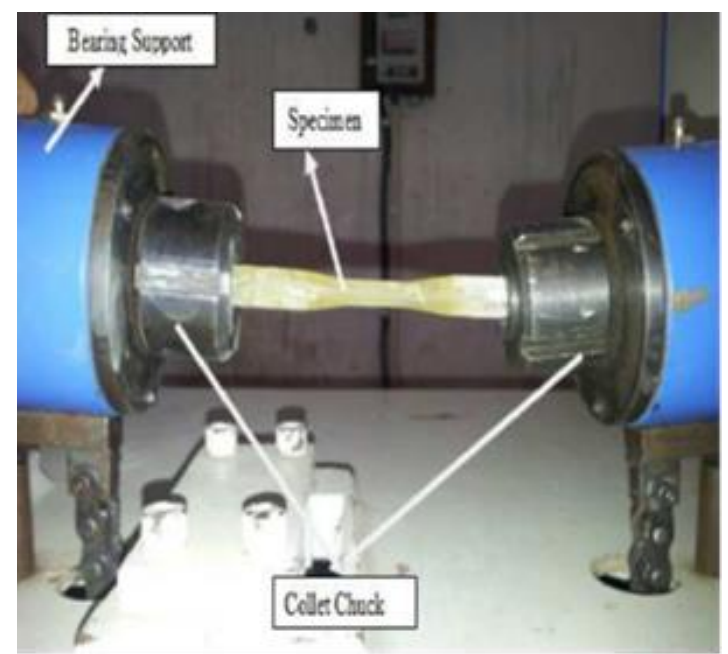

Fig. 1. Stand of fatigue testing [5]

Another stand, which does fatigue testing by exposing metallic samples to solicitations of rotational bending, and simultaneously to friction, can be observed in Fig. 2.

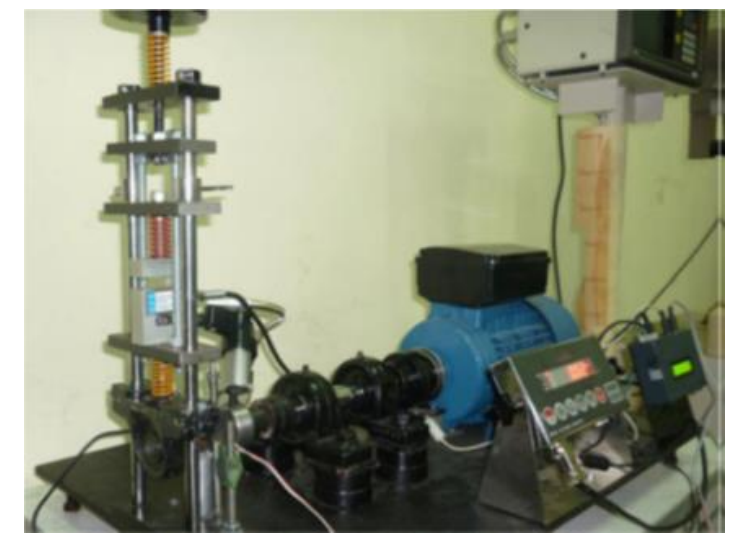

Fig. 2. Rotating bending fretting fatigue test machine [6]

This paper presents various observations on fatigue testing of samples made of epoxy resins, of circular shape and exposed to varied solicitations of bending through a specially created stand for these tests [2].

\section{METHODS AND MATERIALS}

The samples exposed to tests have been made of Epoxy Resins Epiphen RE 4020 and Hardener DE 4020 and casted in tubular molds (Fig. 3). The mixture of the two has been done at room temperature (approximately $23^{\circ} \mathrm{C}$ ), in a mechanical mixer, for 10 minutes. The polymerisation has been done at room temperature, and tests have been done after 50 days of casting.

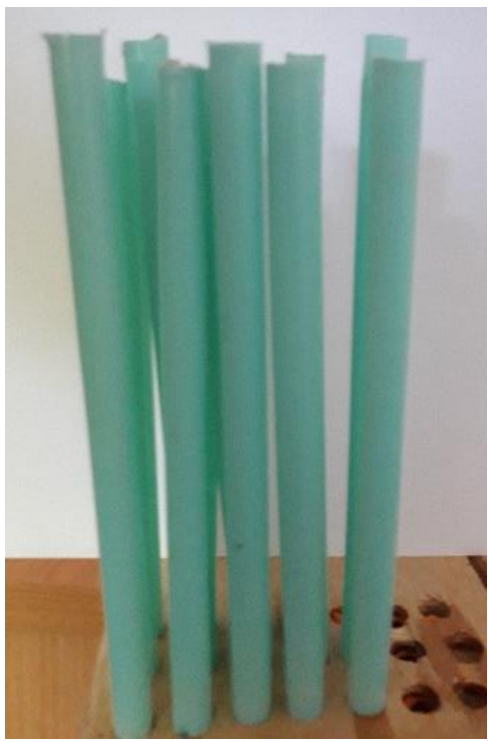

Fig. 3. Samples in tubular moulds.

The samples are circular, have a length of 120 $\mathrm{mm}$ and a diameter of $8 \mathrm{~mm}$. The samples are placed in chucks on a length of $20 \mathrm{~mm}$ of both ends, thus, their final testing length is of $80 \mathrm{~mm}$.

Fatigue tests have been done on a stand made of four types of tests, where the samples have been exposed to cyclic bending solicitations [2].

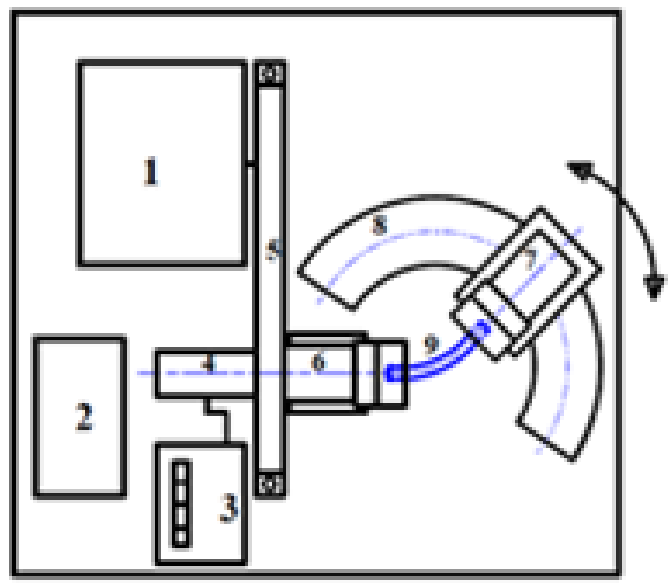

Fig 4. The sketch of the stand

Figure 4 is a sketch of the used stand and contains: 1 - Electric engine; 2 - On-off commuter; 3 - Mechanic meter for showing the number of revolutions; 4 - Transmission mechanism of the shaft rotation to the meter; 5 - Case of the transmission belt; 6 - Driving chuck for fastening the sample; 7 - 
Mobile chuck for holding of the sample; 8 - Sliding surface of mobile chuck; 9- Sample.

The samples have been placed on the stand with the support of a fix chuck (no. 6, Fig. 4) and a mobile chuck (no. 7, Fig. 4), and the stress has been induced on the sample by bending the mobile chuck on a surfaced shaped like a semicircle (no. 8, Fig. 4).

One issue which can come up with this testing method is that at an inclination bigger than 10-12 degrees, the maximum stresses are accumulating in the grip and the area nearby (Fig. 5), thus the tests are inconclusive. In Figure 6, one may observe a sample which broke near the grip.

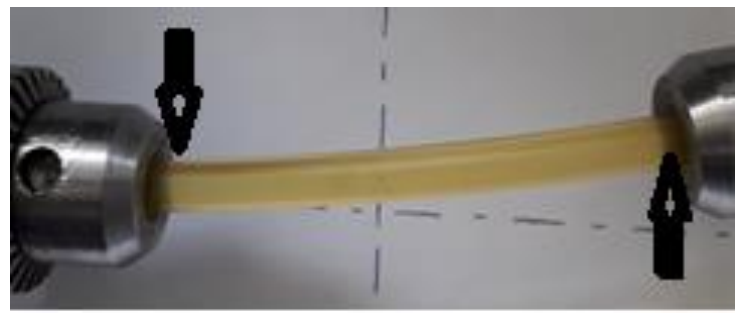

Fig. 5. Concentrated stress in the grip

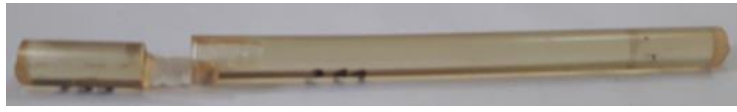

Fig. 6. Sample broken near the grip

To determine the maximum stress concentration in the middle of the sample, a solution was necessary so that, while the mobile chuck is moving on the semicircle surface, it would simultaneously rotate around its own vertical axis. It may be noticed in Fig. 7 the solution which was adopted to create maximum stresses in the middle of the sample. The solution meant that a rod was placed on the horizontal direction of the axis of the mobile chuck, which is supported by a cam at the middle of the rotation circle and which can be adjusted depending on the inclination angle of the sample. With the help of an arch, the rod is in permanent contact with the cam.

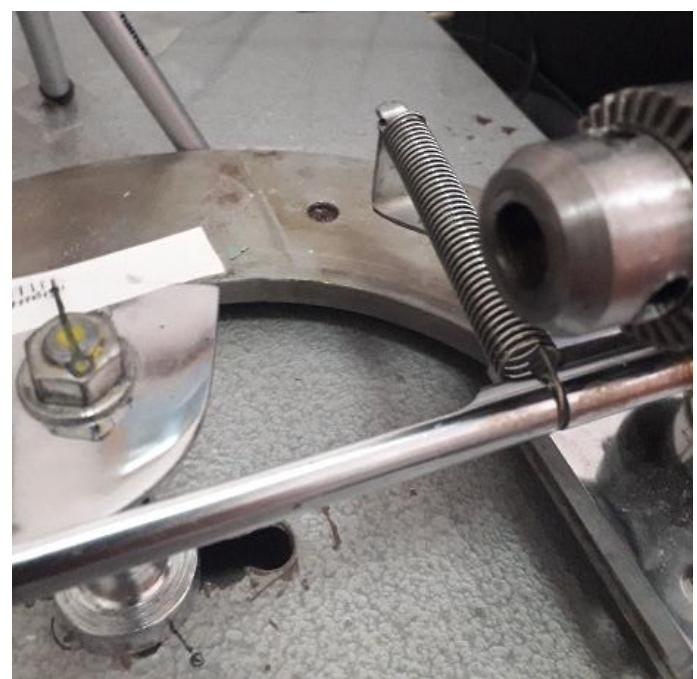

Fig. 7. The solution taken to concentrate stress in the middle of the sample
Another problem that had to be fixed during testing was related to the breaking of the samples from the grip; however, this time, it was due to the type of grip of the chuck. As it can be observed in Fig. 8, the three slips that hold the sample are sharp and go through the material of the sample, creating unwanted concentrations of stress.

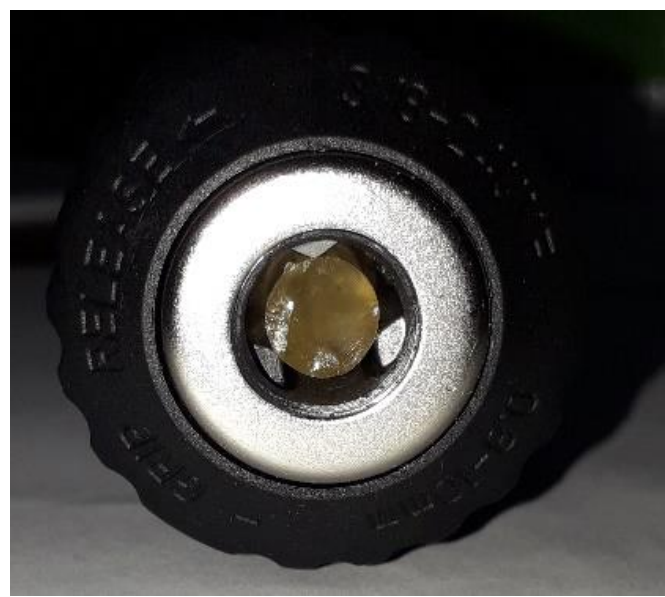

Fig. 8. Chuck with three slips of grip

Figure 9 presents two samples which have been hold in the chuck with three slips. In the first figure, one may see the break caused by the penetration of the slips of the chuck in the samples, and in the second, we can see how the sample was rotated because of the incomplete hold of the chuck.

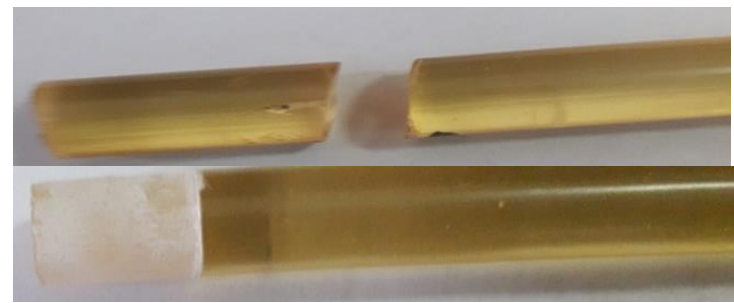

Fig. 9. Failed samples due to the chuck with three holding slips

To manage this issue too, the chuck with three slips have been replaced with other chucks with a grip which was on the entire holding circumference (Fig. 10). Also, these chucks had flared and rounded margins, so that, when bending, it would distort the sample.

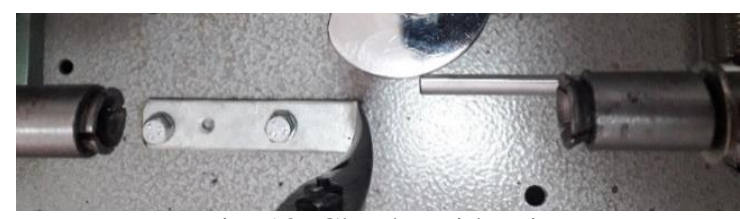

Fig. 10. Chucks with grip

on the entire circumference

During tests, there has been noticed that when the samples are bending at an angle higher than 15 degrees, the system with cam is not enough for concentrating the maximum stresses in the middle of the samples, because of their rigidity. In this case, it 
was opted to create a stress concentrator, after the polymerization. First, the stress concentrator has been created through turning, however the process is difficult because it is hard to obtain an equal circumference for every sample and, as you can see in Fig. 11, after the intervention, the surface resulted has irregularities and the process of removing them is difficult and long-lasting.

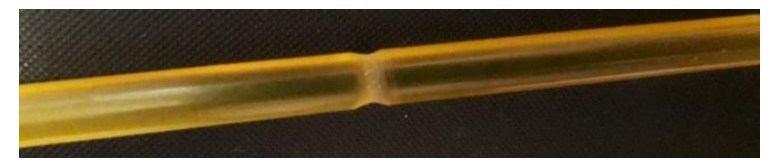

Fig. 11. Sample with stress concentrator, made through turning

In the end, another method to create the stress concentration has been adopted, by making a cut with a tool with a knife and a system to adjust the cut in the material. The knife was adjusted to cut $0.05 \mathrm{~mm}$ in the sample, so that the diameter of the sample has $7.9 \mathrm{~mm}$ in the area. The shape and the measurements of the used knife are shown in Fig. 12.

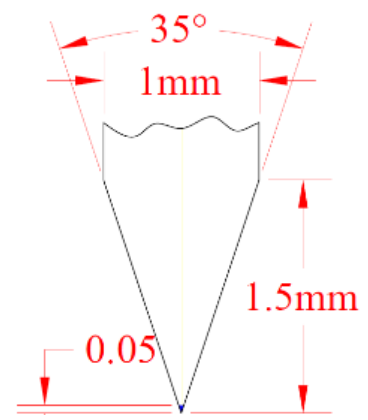

Fig. 12. The shape and the measurements of the used knife

\section{RESULTS}

As a result of the system created from the rod, cam and fixing spring, the stresses have accumulated in the middle of the sample, and the result is that it broke in the area, as one may see in Fig. 13.

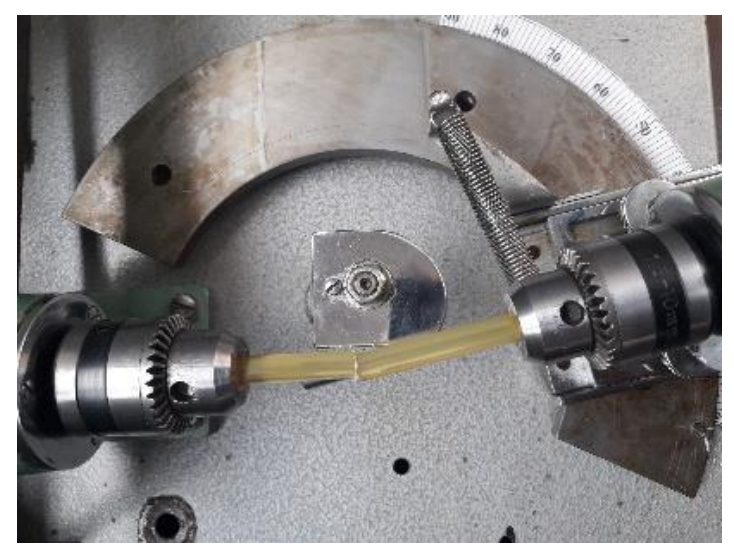

Fig. 13. The break in the middle of the sample

In Figure 14, one may observe, again, that the break of the sample is in the middle, this time, because of the chucks that hold the sample in a grip on its whole circumference and which have flared and rounded margins, just avoiding the deterioration during the bending of the samples.

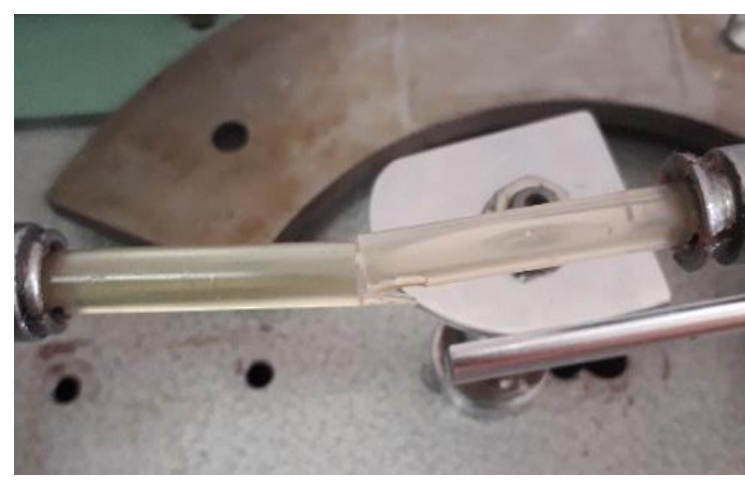

Fig. 14. Sample broken in half

Another method which was implemented to assure the accumulation of stresses in the middle of the samples when the inclination angle is bigger than $15^{\circ}$, was to use a cutting tool. This method doesn't take a long time to execute, has few costs and it easy to make and doesn't require subsequent interventions. The results can be seen in Fig. 15.

In Figure 16, one may see the shape of the break of the sample made of polymeric resins (a) in comparison to a sample made of steal (b), which have been exposed to fatigue solicitations.

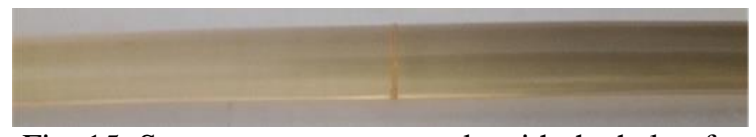

Fig. 15. Stress concentrator made with the help of a cutting tool

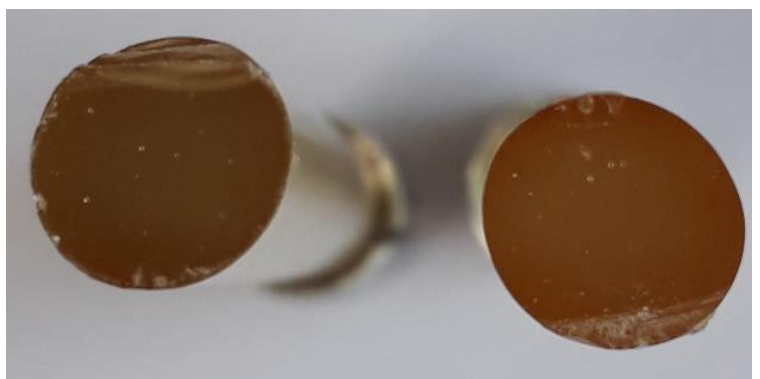

a) epoxy resin

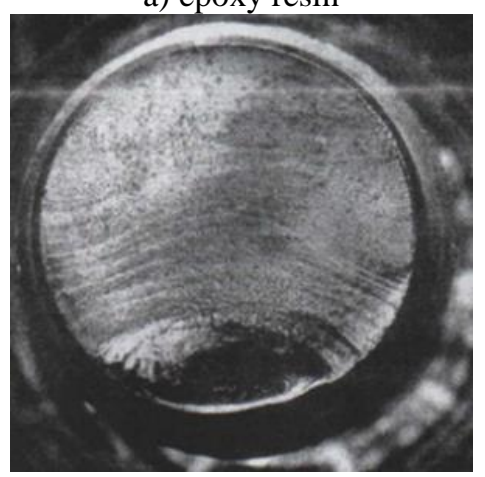

b) metals

Fig. 16. Imagines which breaks caused by fatigue in materials: 
In Figure 17, one may see, from sideways, the shape of the break of a sample made of epoxy polymeric resins, which was exposed to fatigue solicitations though rotational bending.

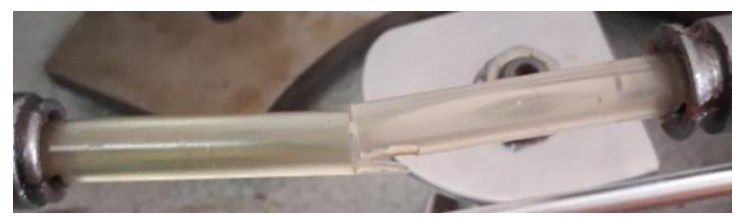

Fig. 17. Break caused by fatigue, sideways view

\section{CONCLUSIONS}

The fatigue testing of epoxy polymers is necessary because we can't anticipate the lifespan of a material confectioned from it.

The used stand for testing the samples by using the method which exposes them to rotational bending is easy to use and manipulate, in comparison to stands which use weights to induce fatigue.

It was necessary to use a method to create stresses in the middle of the samples: rod, cam and spring.

Making fine cuts with a cutting tool was used to concentrate stresses in the middle of the samples when the inclination angle is over $15^{\circ}$.

This stand can be considered usable to make fatigue tests on epoxy materials, taking in consideration the improvement on the stand showcased in this article.

\section{ACKNOWLEDGMENTS}

This work has been supported by the European Social Fund through the Sectorial Operational Programme Human Capital 2014-2020, through the Financial Agreement with the title ,Burse pentru educaţia antreprenorială în rândul doctoranzilor și cercetătorilor post doctorat (Be Antreprenor!)" "Scholarships for entrepreneurial education among doctoral students and postdoctoral researchers (Be Entrepreneur!)", Contract no. 51680/09.07. 2019 SMIS code: 124539.

\section{REFERENCES}

[1] Humelnicu C., Mereuta E., Amortila V., Gingarasu M. (2019) Fatigue polymeric materials-air pollution factor, International Multidisciplinary Scientific GeoConference: SGEM, 19(4.2), pp. 221228 ,

[2] Humelnicu C., Amortila V., Gingarasu M., Mereuta E. (2018) Damaging by tribo-fatigue and test rig design, International Multidisciplinary Scientific GeoConference: SGEM, 18(4.3), pp. 235242.

[3] ***Argus Leader: Sioux Falls Landfill Tightens Rules After Minnesota Dumps Dozens of Wind Turbine Blades, American Experiment, August 30 (2019).

https://www.americanexperiment.org/2019/08/argusleader-sioux-falls-landfill-tightens-rules-minnesotadumps-dozens-wind-turbine-blades/ (accessed Apr. $21,2020)$.

[4] *** The ultimate argument to buy a new hanse sailing yacht now..... Royal Sailing, http://www.royalsailing.com/ (accessed Apr. 26, 2020).

[5] Ujjwal M., Mrinalini R., Amritpreet S. (2015) Analysis of fatigue behavior of glass/carbon fiber epoxy composite, International Journal of Research in Engineering and Technology, 4(4), pp. 211-216, Apr. 2015, doi: 10.15623/ijret.2015.0404038.

[6] Zalnezhad E.,. Sarhan A. A. D, Jahanshahi P. (2013) A new fretting fatigue testing machine design, utilizing rotating-bending principle approach, International Journal of Advanced Manufunturing Technology, doi: 10.1007/S00170-013-5457-0. 